\title{
Minimal dose of aerosolized interferon- $\alpha$ in human subjects: biological consequences and side-effects
}

\author{
S. Giosuè*, M. Casarini*, F. Ameglio**, L. Alemanno**, C. Saltini+, A. Bisetti*
}

Minimal dose of aerosolized interferon- $\alpha$ in human subjects: biological consequences and side-effects. S. Giosuè, M. Casarini, F. Ameglio, L. Alemanno, C. Saltini, A. Bisetti. (C)ERS Journals 1996.

ABSTRACT: Interferon- $\alpha($ IFN- $\alpha)$ is a leucocyte-derived cytokine with pleiotropic effects on the cells of the immune system, including the ability to promote viral and microbial killing. This study was designed to evaluate the biologically active dosage of aerosolized lymphoblastoid IFN- $\alpha$, in normal subjects and patients with chronic bronchitis, using serum 2'-5' oligoadenylate synthetase (OAS) as a marker of IFN- $\alpha$ actitivity.

Three groups of subjects were included: two healthy groups and one of patients with chronic bronchitis. Group A (controls, $n=5$ ) was studied in order to determine the minimal IFN- $\alpha$ dose able to induce biological effects without side-effects. IFN- $\alpha$ was given in a dose escalation trial including $0,0.3 \times 10^{6}, 1.0 \times 10^{6}$ and $3.0 \times 10^{6}$ IU $\cdot$ day $^{-1}$ (5 day administration). Only the administration of $3.0 \times 10^{6} \mathrm{IU} \cdot \mathrm{day}^{-1}$ of IFN$\alpha$ induced a significant biological activity, increasing serum levels of OAS. Group $B$ (controls, $n=5$ ) and $\mathrm{C}$ (chronic bronchitis, $\mathrm{n}=5$ ) were given $3.0 \times 10^{6} \mathrm{IU}^{\circ} \mathrm{day}^{-1}(10$ day administration) in order to study serum, bronchoalveolar lavage fluid (BALF) and BALF cell modifications, after treatment. OAS serum levels and nitroblue tetrazolium (NBT) reduction tests, the latter used as a measure of phagocyte cell activity, increased both in normal subjects and in patients with chronic bronchitis. No significant change of serum IFN- $\alpha$ levels was found.

It is concluded that aerosolized IFN- $\alpha$ administration to the lung is well-tolerated at biologically active doses. The activity can be monitored by quantifying OAS serum levels through a simple blood test.

Eur Respir J., 1996, 9, 42-46.

\begin{abstract}
*Dipartimento di Scienze Cardiovascolari e Respiratorie, Ospedale Carlo Forlanini, Università "La Sapienza", Rome, Italy. **Istituto di Ricerca San Gallicano, Rome, Italy. +Dipartimento di Scienze Mediche, Oncologiche e Radiologiche, Università di Modena, Modena, Italy.
\end{abstract}

Correspondence: S. Giosuè

Via dei Gonzaga 37

00164 Rome

Italy

Keywords: Aerosol

bronchoalveolar lavage fluid

chronic bronchitis

interferon- $\alpha$

tetrazolium reduction

oligoadenylate synthetase

Received: March 151995

Accepted after revision August 171995
The lung deals with inhaled particles by removing them through its clearance system and, eventually, by destroying them by means of the resident immune cells, which include alveolar macrophages and lymphocytes [1]. In vitro evaluation of immune cells recovered from the epithelial surface of the lower respiratory tract of normal individuals has shown that they are "compartmentalized" to the alveolar epithelial surface from the systemic immune effector cells [2].

All interferons (IFNs) exert powerful immunomodulatory effects over the cells of the immune system; therefore, IFNs could represent a useful therapeutic approach to control respiratory tract diseases, such as neoplasms or infections, by boosting the local lung immune system [3]. In addition to the immunostimulating effect, IFNs exert antiviral [4] and antibacterial [5] activities, thus representing a potentially powerful drug to be used in several infections, such as viral pneumonias or relapses of chronic bronchitis.

Results obtained in IFN- $\alpha$ clinical trials aimed to treat primary or metastatic lung tumours have shown that, in order to attain therapeutic lung levels by intravenous or intramuscular administration, it is necessary to give very high doses of IFN- $\alpha$, generally with an augmented risk of severe side-effects.

IFN- $\alpha$ may also be administered as an aerosol, a route employed since 1984 [6, 7]. This route may be advantageous because IFN- $\alpha$ may locally activate the spectrum of immunocompetent bronchoalveolar cells producing only mild if any side-effects, being inactivated during the transalveolar passage [8]. Previous studies using inhaled IFNs, generally aimed to treat neoplasm, have been described in the literature, [9-12]. Knowledge of the local effect of IFN- $\alpha$ could support its therapeutic use, especially when low dosing could reduce or avoid systemic side-effects [8, 13].

This study was designed to evaluate the biologically active dose of aerosolized IFN- $\alpha$. A dose escalation study of lymphoblastoid IFN- $\alpha$ inhalation was performed, with the aim of determining the minimal inhaled dose able to induce biological effects without side-effects. For this purpose, as a marker of IFN- $\alpha$ activity, the 2'5 'oligoadenylate synthetase (OAS) was selected. In fact, it is known that the cells treated with IFNs synthetize 
different amounts of various forms of OAS [14]. Some of these forms confer resistance to picornavirus infection, probably through ribonuclease (RNase) activation [14]. Although the involvement of OAS in viral inhibition needs further clarification, a relationship between OAS synthesis and IFN induction is definitely accepted [14].

\section{Material and methods}

\section{Patients}

Three groups of subjects were included in the study: two healthy groups (A and B) and a third group consisting of patients with chronic bronchitis (C).

Group A. Five nonsmoking healthy volunteers (median age 29, range 25-48 yrs), 4 males and 1 female, with normal respiratory function tests and without history of chronic respiratory diseases.

Group B. Five nonsmoking healthy volunteers (median age 50, range 46-57 yrs), 4 males and 1 female, with normal respiratory function tests and without history of chronic respiratory diseases.

Group C. Five nonsmoking patients with chronic bronchitis in a disease period far from relapse (median age 52, range 47-57 yrs) 4 males and 1 female, with pulmonary function adequate for effective inhalation forced expiratory volume in one second $(\mathrm{FEV} 1)>70 \%$ of predicted value. Chronic bronchitis was defined according to ECSC (European Coal and Steel Community) $[15,16]$.

Neither the healthy controls nor the patients complained of concurrent diseases. Informed consent was obtained from all subjects and the study was approved by the Ethics Committee of the C. Forlanini Hospital.

\section{IFN- $\alpha$ inhalation}

Lymphoblastoid IFN- $\alpha$ (Wellferon, Wellcome) was given by an IS-2 jet nebulizer operating on compressed air (Pari, Starnberg, Germany), generating a total output of $0.32 \mathrm{~g} \cdot \mathrm{min}^{-1}$, at an inspiratory flow of $20 \mathrm{~L} \cdot \mathrm{min}^{-1}$, delivery time $4 \mathrm{~min}$ and $1 \mathrm{~mL}$ volume delivered, $90 \%$ droplets $<4.8 \mu$ in size. To dilute IFN- $\alpha 0.9 \% \mathrm{NaCl}$ solution was employed.

IFN- $\alpha$ was given in a solution of $1 \mathrm{mg} \cdot \mathrm{mL}^{-1}$ human albumin (Human Albumin Alone, Immuno, Italy). The IFN- $\alpha$ amounts administered are not comparable to those received. Throughout this text, the definition of the administered dose is equivalent to the aerosolized dose.

Group A was employed to determine the minimal IFN$\alpha$ dosage able to induce biological effects without sideeffects. IFN- $\alpha$ was given in a dose escalation trial at 0 (placebo), $0.3 \times 10^{6}, 1.0 \times 10^{6}$ and $3.0 \times 10^{6} \mathrm{IU}^{\mathrm{day}}{ }^{-1}$ (5 day administration). Two subsequent cycles were separated by a $48 \mathrm{~h}$ interval. Blood samples were taken to be tested $24 \mathrm{~h}$ after the fifth dose of each cycle.
Groups B and C were given $3.0 \times 10^{6} \mathrm{IU}^{- \text {day }^{-1}}$ (10 day administration). Blood samples were taken $24 \mathrm{~h}$ after treatment with the 10th dose. B and C groups were employed to study the effects of the treatment on serum, bronchoalveolar lavage fluid (BALF) and BALF cells. Group A was not employed for BALF collection.

\section{Bronchoalveolar lavage fluid}

BALF was collected during fibreoptic bronchoscopy under local anaesthesia.

The bronchoscope was inserted in a subsegment of the lung middle lobe. A standard lavage protocol was performed by infusing five times $20 \mathrm{~mL}$ aliquots (a total of $100 \mathrm{~mL}$ ) of sterile $0.9 \%$ saline, at body temperature, through the aspiration port. After each aliquot, lavage was collected via the same port into a plastic trap using wall suction [17].

Portions of BALF were used to determine the total cell number and cell differential count, after cytocentrifuge preparations.

\section{BALF cell preparation}

After BALF centrifugation at $1,200 \times \mathrm{g} \cdot \mathrm{min}^{-1} \times 10 \mathrm{~min}$, cells were washed and resuspended in RPMI (2.5 million $\left.\cdot \mathrm{mL}^{-1}\right)$. An aliquot of BALF cell preparation was stored in liquid nitrogen.

\section{Serum determinations}

IFN- $\alpha$ (or lymphoblastoid IFN or leucocyte IFN) was determined by means of a commercially available enzyme immunoassay kit (IFN-alpha EIA, Anawa SA, Zurich, Switzerland) following the manufacturer's indications. The test measures all subtypes of IFN- $\alpha$ through a standard curve generated using recombinant IFN-alpha2b. Method sensitivity is $0.2 \mathrm{U}$ of IFN-alpha2b. One $\mathrm{U}$ of this interferon type is equivalent to $2.8 \mathrm{U}$ of leucocyte interferons. IFN-alpha2b U have been used in this study.

Neopterin (NEO, ng. $\mathrm{mL}^{-1}$ ), a macrophage activation marker, sensitive to IFN activity [18], was detected by using a radioimmunoassay (RIA) kit produced by Sorin, Saluggia, Italy (sensitivity $\left.=0.4 \mathrm{ng} \cdot \mathrm{mL}^{-1}\right)$. Beta $_{2}$-microglobulin $\left(\beta_{2} \mathrm{M}, \mu \mathrm{g} \cdot \mathrm{L}^{-1}\right)$, a soluble membrane component induced by all interferons [19], was measured using the $\beta_{2}$-microglobulin MEIA kit, produced by Abbott Laboratories, Chicago, USA (sensitivity $=6 \mu \mathrm{g} \cdot \mathrm{L}^{-1}$ ). Finally, the 2'-5' oligoadenylate synthetase (OAS, $\left.\mathrm{pmol} \cdot \mathrm{dL}^{-1}\right)$, an enzyme induced by IFN- $\alpha$, was evaluated by the RIA kit 2'-5' AS produced by EIKEN Chemicals, Japan (sensitivity $=10 \mathrm{pmol} \cdot \mathrm{dL}^{-1}$ ) [20].

\section{Nitroblue tetrazolium (NBT) reduction}

NBT is a clear, yellow, water soluble compound; on reduction it forms formazan, a deep blue-dye. 
Washed BALF cells were incubated with NBT solution and the NBT reduction could be quantitated by reading the optical density (OD) at $570 \mathrm{~nm}$. This measure may be considered an overall metabolic index of integrity of phagocytosing cells [21].

\section{Phagocytosis determination}

Phagocytosis analysis was performed by using plastic beads. After $2 \mathrm{~h}$ incubation at $37^{\circ} \mathrm{C}, 5 \% \mathrm{CO}_{2}$, freshly sonicated and opsonized plastic beads, resuspended in foetal calf serum free medium (RPMI 1640), added to $1 \times 10^{5}$ BAL cells, were washed and reincubated for $1 \mathrm{~h}$. After additional washing, cells were microscopically observed and phagocytosed beads counted. The results were expressed as mean bead number per cell [21].

\section{Safety of treatment}

Vital signs (blood pressure, heart rate, respiratory rate, temperature), blood cell counts (BCC), erythrocyte sedimentation rate (ESR) and pulmonary function, vital capacity (VC), forced expiratory flow in one second (FEV1), and transfer factor of the lungs for carbon monoxide (TL,CO), evaluated by MasterLab Transfer Spirometer, Jaeger, Germany, were measured before and after the treatment.

\section{Statistical analysis}

Due to the limited number of subjects included in each group and to the lack of knowledge regarding the distribution of individual variables studied, only nonparametric statistical tests were used.

Comparisons between two paired groups (pre- versus post-IFN- $\alpha$ treatment) were performed by using the Wilcoxon rank test. When more than two groups were compared, the Friedman one-way analysis of variance (ANOVA) test was employed. To compare unpaired groups, the Mann-Whitney test was used, whilst the Wilcoxon rank test was used to compare paired groups. Frequency analysis was obtained by using the chi-squared test.

\section{Results}

\section{Safety monitoring}

Neither healthy controls (Groups A and B) nor the patients (Group C) showed significant changes regarding blood pressure, respiratory rate, temperature, ESR, BCC, VC, FEV1 and TL,CO (data not shown).

\section{IFN- $\alpha$ biological effect}

Figure 1 shows serum modifications determined by all the IFN- $\alpha$ doses $\left(0.3 \times 10^{6}, 1.0 \times 10^{6}\right.$ and $3.0 \times 10^{6} \mathrm{IU}^{-}$day $\left.^{-1}\right)$

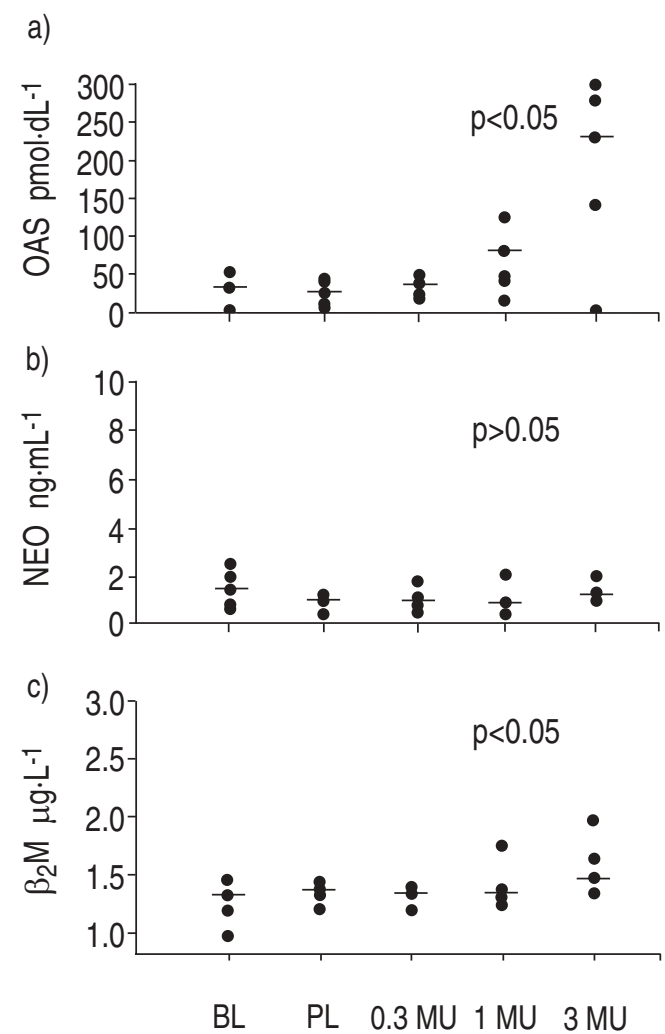

Fig. 1. - Effect of different doses of interferon- $\alpha$ (IFN- $\alpha$ ) treatment administered daily for 5 days in serum of normal subjects. Individual points with bar indicating median are shown. a) OAS: 2'5' oligoadenylate synthetase; b) NEO: neopterin; c) $\beta_{2}-\mathrm{M}: \beta_{2^{-}}$ microglobulin. Blood samples were obtained $24 \mathrm{~h}$ before (BL: baseline) and $24 \mathrm{~h}$ after the end of treatment (PL: placebo, 0.3 MU IFN- $\alpha$ ). Statistical analysis was performed by the Friedman test. Serum OAS levels found in subjects treated with 3 MU of IFN- $\alpha$ were statistically different (Wilcoxon rank test) as compared to those found in all the other groups (baseline + placebo + 0.3 MU + $1 \mathrm{MU} ; \mathrm{p}<0.05$ ). A significant trend was also noted for $\beta_{2}-\mathrm{M}$ (Friedman test; $\mathrm{p}<0.05$ ); MU: million units.

Table 1. - Bronchoalveolar lavage fluid (BALF) cells pre- and post-IFN- $\alpha$ treatment $\left(3 \times 10^{6}\right.$ IU.day $\left.{ }^{-1}\right)$

\begin{tabular}{|c|c|c|c|c|}
\hline & \multicolumn{2}{|c|}{$\begin{array}{l}\text { Normal subjects } \\
\text { (Group B })\end{array}$} & \multicolumn{2}{|c|}{$\begin{array}{c}\text { Patients } \\
\text { (Group C) }\end{array}$} \\
\hline & $\begin{array}{l}\text { Pre- } \\
\text { IFN- } \alpha\end{array}$ & $\begin{array}{l}\text { Post- } \\
\text { IFN- } \alpha\end{array}$ & $\begin{array}{l}\text { Pre- } \\
\text { IFN- } \alpha\end{array}$ & $\begin{array}{l}\text { Post- } \\
\text { IFN- } \alpha\end{array}$ \\
\hline Recovery $\mathrm{mL}$ & $61 \pm 2$ & $60 \pm 3$ & $59 \pm 3$ & $58 \pm 2$ \\
\hline Total cells $\times 10^{4} \cdot \mathrm{mL}^{-1}$ & $2.15 \pm 0.3$ & $2.24 \pm 0.35$ & $2.28 \pm 0.3$ & $2.3 \pm 0.3$ \\
\hline Macrophages \% & $87 \pm 3.5$ & $88 \pm 4.1$ & $85 \pm 3.8$ & $84 \pm 4.7$ \\
\hline Lymphocytes \% & $10 \pm 1.2$ & $9 \pm 1.5$ & $8 \pm 0.9$ & $8 \pm 1$ \\
\hline Neutrophil \% & $3 \pm 0.2$ & $3 \pm 0.4$ & $7 \pm 0.8$ & $8 \pm 0.9$ \\
\hline Eosinophils \% & 0 & 0 & 0 & 0 \\
\hline
\end{tabular}

Values are presented as mean \pm SD. For characteristics of the groups see "Patients and methods". Wilcoxon rank test was used to compare the two groups. No significant differences were found between pre- and post-IFN- $\alpha$ treatment both in Groups B and C. Comparing Group B vs C, only neutrophil levels were significantly different both in pre- and post-IFN- $\alpha$ treatment $(\mathrm{p}<0.05)$ IFN- $\alpha$ : interferon- $\alpha$. 
Table 2. - Median serum and BALF values of OAS, IFN- $\alpha$ and NBT in normal subjects (Group B), chronic bronchitic patients $24 \mathrm{~h}$ before (Pre), the first and $24 \mathrm{~h}$ after (Post) the last dose of IFN- $\alpha$ treatment $\left(3 \times 10^{6}\right.$ IU.day $\left.{ }^{-1}\right)$

\begin{tabular}{|c|c|c|c|c|c|c|c|c|}
\hline & \multicolumn{4}{|c|}{ OAS $\mathrm{pmol} \cdot \mathrm{dL}^{-1}$} & \multicolumn{2}{|c|}{ IFN- $\alpha$} & \multicolumn{2}{|c|}{ NBT } \\
\hline & \multicolumn{2}{|c|}{ Pre } & \multicolumn{2}{|c|}{ Post } & \multirow{2}{*}{$\begin{array}{c}\text { Pre } \\
\text { Serum }\end{array}$} & \multirow{2}{*}{$\begin{array}{l}\text { Post } \\
\text { Serum }\end{array}$} & \multirow{2}{*}{$\begin{array}{c}\text { Pre } \\
\text { BALF }\end{array}$} & \multirow{2}{*}{$\begin{array}{l}\text { Post } \\
\text { BALF }\end{array}$} \\
\hline & BALF & Serum & BALF & Serum & & & & \\
\hline \multicolumn{9}{|l|}{ Group B } \\
\hline Subject 1 & $<10$ & 28 & $<10$ & 180 & 0.23 & $<0.2$ & 0.05 & 0.128 \\
\hline 2 & $<10$ & 160 & $<10$ & 170 & $<0.2$ & $<0.2$ & 0.104 & 0.146 \\
\hline 3 & $<10$ & 15 & $<10$ & 33 & 0.28 & 0.34 & 0.02 & 0.452 \\
\hline 4 & $<10$ & 13 & $<10$ & 41 & $<0.2$ & $<0.2$ & 0.002 & 0.037 \\
\hline 5 & $<10$ & $<10$ & $<10$ & 43 & $<0.2$ & $<0.2$ & 0.044 & 0.089 \\
\hline \multicolumn{9}{|l|}{ Group C } \\
\hline Patient 1 & 17.3 & 37 & 35.7 & 462 & $<0.2$ & 0.26 & 0.104 & 0.146 \\
\hline 2 & 13.9 & 112 & 17.9 & 214 & 0.45 & 0.47 & 0.05 & 0.128 \\
\hline 3 & $<10$ & 100 & 20.6 & 147 & $<0.2$ & $<0.2$ & 0.05 & 0.037 \\
\hline 4 & $<10$ & 20 & 15.2 & 118 & $<0.2$ & $<0.2$ & 0.016 & 0.049 \\
\hline 5 & $<10$ & $<10$ & 15.0 & 130 & 0.37 & 0.34 & 0.044 & 0.089 \\
\hline
\end{tabular}

OAS: 2'-5' oligoadenylate synthetase; NBT: nirtoblue tetrazolium reduction (OD 570); BALF: bronchoalveolar lavage fluid; OD: optical density; IFN- $\alpha$ : interferon- $\alpha$ (IFN- $\alpha 2 b)$ U. For characteristics of the group see "Patients and methods". Wilcoxon rank test was used to compare the two groups. Significances are reported in the text.

compared both to pretreatment condition and to placebo, regarding NEO, $\beta_{2} \mathrm{M}$ and OAS. One subject in Group A had no OAS induction, increasing the interindividual variability of this group. No significant change was observed for NEO, but an increasing trend for $\beta_{2} \mathrm{M}$ (Friedman test; $\mathrm{p}<0.05$ ) and a significant difference for $\mathrm{OAS}$ at the highest IFN- $\alpha$ dose (Wilcoxon Rank test; $\mathrm{p}<0.05)$ were seen.

No BALF collection was performed in Group A. In contrast, both Groups B and C were employed for serum and BALF collection. Since only $3.0 \times 10^{6} \mathrm{IU} \cdot \mathrm{day}^{-1}$ of IFN- $\alpha$ was able to induce a significant OAS increase, this amount was used through the subsequent experiments.

Table 1 reports the BALF cell numbers observed in normal subjects (Group B) and chronic bronchitis patients (Group C) before and after treatment with $3 \times 10^{6} \mathrm{IU} \cdot \mathrm{day}^{-1}$ of IFN- $\alpha$. Neutrophil percentages were significantly higher in Group $\mathrm{C} v s$ B, both before and after IFN- $\alpha$ treatment (Wilcoxon rank test; $\mathrm{p}<0.05$ ). No changes in BALF cells were observed after treatment.

Table 2 shows the individual values of OAS (BALF and serum), serum IFN- $\alpha$ and NBT (BAL cells) determined both in normal subjects and in patients with chronic bronchitis (Groups B and C). IFN- $\alpha$ levels in sera were, in general, not detectable. NBT values showed increased median levels both in Groups B and C after treatment (Wilcoxon rank test; $\mathrm{p}<0.05$ ). OAS showed significant increases in serum levels in controls and in patients with chronic bronchitis after treatment (Wilcoxon rank test; $\mathrm{p}<0.05)$. In constrast, OAS levels in the BALF were significantly elevated after IFN- $\alpha$ treatment only in the patients with chronic bronchitis (Wilcoxon rank test; $p<0.05$ ) (table 2). No differences were found for phagocytic activity of BALF cells (data not shown).

\section{Discussion}

The administration of aerosolized IFN- $\alpha$, within the range considered, was well-tolerated, without significant vital sign alterations (see methods). Pulmonary function remained unchanged both in normal subjects and chronic bronchitis patients, as expected from the literature. Severe side-effects have previously been noted only at very high doses, such as those given for control of lung cancer. The aim of this research was to determine the lowest inhaled IFN- $\alpha$ dosage able to induce a detectable biological effect. For this purpose, increasing IFN- $\alpha$ doses, between 0 to $3.0 \times 10^{6} \mathrm{IU} \cdot$ day $^{-1}$, were administered to five normal subjects.

Only at the highest dose $\left(3.0 \times 10^{6} \mathrm{IU} \cdot \mathrm{day}^{-1}\right)$ was one of three serum markers of IFN activity, namely OAS, significantly increased by the treatment (placebo vs $3.0 \times 10^{6}$ IU. day $^{-1}$; Wilcoxon rank test; $\mathrm{p}<0.05$ ). A progressively increasing trend was also observed for $\beta_{2} \mathrm{M}$ (Friedman test; $\mathrm{p}<0.05)$, another marker enhanced by IFN [19]. As shown in figure 1 , one of the subjects receiving inhaled IFN- $\alpha$, did not show a response. This finding may be explained by the already reported IFN- $\alpha$ resistance. It must be noted that the method used in this study to measure the OAS levels is a functional system which ensures that OAS is an active enzyme.

To confirm the OAS increase, another group of healthy volunteers (Group B) and a group of patients with chronic

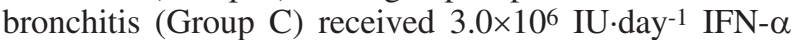
to study in greater detail both serum OAS and IFN- $\alpha$ modifications as well as the variation of the cellular spectrum found in BALF. In these last two groups, serum OAS levels clearly increased following treatment. No significant change of serum IFN- $\alpha$ levels was found after aerosolized IFN- $\alpha$ administration, suggesting that the serum levels of IFN- $\alpha$ were not correlated to the amount 
of IFN- $\alpha$ administered, but may be due to IFN- $\alpha$ inactivation at the alveolar level, as reported previously [7]. Alternatively, we cannot rule out that the sensitivity of the test used for IFN- $\alpha$ detection was not sufficient to evaluate very small serum IFN- $\alpha$ changes. It is also important to remember that the IFN- $\alpha$ half-life is very short [22].

When the BALF OAS levels were determined, a signigicant OAS increase was observed only in Group C. This finding may possibly be explained by the high BALF dilution rate. In fact, as previously reported [23], a mean epithelial lung fluid/BAL ratio of $1: 100$ has been observed when a standard BAL collection was performed. Thus, is it not suprising that the BALF OAS levels are lower than serum OAS levels. In fact the BALF OAS levels must be multiplied by 100 on average, as evaluated by urea method [23], in accordance with literature data.

In the case of Group B (healthy subjects) possible increases in the OAS levels may have been below the detection limit. By contrast, in Group C (bronchitis patients) the BALF OAS levels were sufficiently high to be measured, and significant changes could be observed between pre- and post-IFN- $\alpha$ treatment.

OAS production has been reported to be linked both to cell synthesis and to cell lysis. The present study cannot differentiate between these two mechanisms, although the lack of significant differences between the BALF cell numbers before and after IFN- $\alpha$ administration suggests that cell lysis does not represent a major event.

Although many questions remain unresolved concerning OAS production, an association between IFN- $\alpha$ induction and OAS synthesis is now well-documented, indicating that serum and BALF OAS changes are strictly dependend on IFN- $\alpha$ activity [14].

In conclusion, these data provide the rationale for designing clinical trials on aerosolized IFN- $\alpha$ therapy in chronic lung disorders, using serum OAS to monitor IFN$\alpha$ activity.

\section{References}

1. Saltini C, Kirby M, Bisetti A, Crystal RG. The lung immune system. J Immunol Res 1991; 3: 43-48.

2. Saltini C, Kirby M, Trapnell B,Tamura N, Crystal RG. Biased accumulation of T-lymphocytes with "memory"type CD45 leukocytes common antigen gene expression on the epithelial surface of the human lung. J Exp Med 1990; 171: 1123-1140.

3. Baren S, Stanton G, Fleischmann WR. Jr, Dianzani F, eds. In: The interferon system: a current review to 1987. Austin; University of Texas Medical Press, 1987; pp. 21-30.

4. Greenberg SB. Human interferon in viral disease. Infect Dis Clin North Am 1987; 1: 383-423.

5. Ho M. Interferon for the treatment of infections. Ann Rev Med 1987; 38: 51-59.

6. Bocci V. Evaluation of routes of administration of interferon in cancer: a review and proposal. Cancer Drug Deliv 1984; 1: 337-340.

7. Bocci V. Pharmacokinetics of interferons and routes of administration. Interferon. Principles and Medical Application. In: Baron S, Coppenhaver DH, Dianzani F, et al, eds. UTMB Press, 1992; pp. 417-425.

8. Bocci V, Pessina GP, Paccini A, Paulesu L, Muscettola M, Mogensen KE. Pulmonary catabolism of interferons: alveolar absorption of ${ }^{125}$ I-labelled human interferonalpha is accompanied by partial loss of biological activity. Antiviral Res 1984; 4: 211-222.

9. Van Zandwijk N, Jassen E, Dubbelmann R, Braat MCP, Rumke P. Aerosol application of interferon-alpha in the treatment of bronchioloalveolar carcinoma. Eur J Cancer 1990; 26: 738-740.

10. Kinnula V, Cantell K, Mattson K. Effect of inhaled natural interferon-alpha on diffuse bronchoalveolar carcinoma. Eur J Cancer 1990; 26: 740-741.

11. Debs RJ, Fuchs HJ, Philip R, et al. Lung-specific delivery of cytokines induces sustained pulmonary and systemic immunomodulation in rats. J Immunol 1988; 140: 3482-3488.

12. Maasilta P, Halme M, Mattson K, Cantell K. Pharmacokinetics of inhaled recombinant and natural alpha-interferon. Lancet 1991; 337: 371.

13. Kinnula V, Mattson K, Cantell K. Pharmacokinetics and toxicity of inhaled human interferon- $\alpha$ in patients with lung cancer. J Interferon Res 1989; 9: 419-423.

14. Chebath J, Revel M. The 2-5 A System: 2-5 A Synthetases, Isospecies and Functions. In: Interferon. Principles and Medical Application. Baron S, Coppenhaver DH, Dianzani F, et al, eds. UTMB Press, 1992; pp. 225-236.

15. Medical Reserch Council. Definition and classification of chronic bronchitis for clinical and epidemiological purposes. Lancet 1965; 1: 775-779.

16. Fletcher CM, Pride NB. Definitions of emphysema, chronic bronchitis, asthma and airflow obstruction: 25 years from the CIBA symposium. Thorax 1984; 39: 81-85.

17. Technical recommendations and guidelines for bronchoalveolar lavage (BAL). Report of the SEP Task Group on BAL. Eur Respir J 1989; 2: 561-585.

18. Fuchs D, Hansen A, Reibnegger G. Neopterin as marker for activated cell-mediated immunity; application to HIV infection. Immunol Today 1988; 9: 150-155.

19. Dolei A, Ameglio F, Capobianchi MR. Human Interferon$\gamma$ enhances the expression of class I and class II major histocompatibility complex products in neoplastic cells more effectively than Interferon- $\alpha$ and Interferon- $\beta$. Infect Immun 1983; 40: 172-176.

20. Merritt JA, Borden EC, Ball LA. Measurement of 2'-5' oligoadenylate synthetase in patients receiving interferon- $\alpha$. J Interferon Res 1985; 5: 191-198.

21. Adams DO. Methods for studying mononuclear phagocytes. New York, Academic Press, 1981.

22. Boutin C, Viallat JR, Van Zandwiyk N, et al. Activity of intrapleural recombinant gamma-interferon in malignant mesothelioma. Cancer 1991; 67: 2033-2037.

23. Rennard SI, Basset G, Lecossier D, et al. Estimation of volume of epithelial lining fluid recovered by lavage using urea as marker of dilution. J Appl Physiol 1986; 60(2): 532-538. 